\title{
Comparative Study of the Outcomes of Percutaneous Endoscopic Lumbar Discectomy and Microscopic Lumbar Discectomy Using the Tubular Retractor System Based on the VAS, ODI, and SF-36
}

\author{
Sang Mok Yoon, Soon-Seob Ahn, Ki Hong Kim, Young Don Kim, \\ Jae Hoon Cho, Dae-Hyun Kim \\ Department of Neurosurgery, College of Medicine, Daegu, Catholic University of Daegu, Korea
}

\begin{abstract}
Objective: Percutaneous endoscopic lumbar discectomy (PELD) and microdiscectomy with the microscope endoscopic tubular retractor system (METRx-MD) are considered popular minimally invasive surgery (MIS) methods for the treatment of lumbar disc herniation. Many authors have also reported good clinical outcomes of these methods, but there are few comparative studies of them. This report compares the clinical outcomes of PELD and METRX-MD for lumbar disc herniation as MIS methods and discusses the efficacy of PELD.

Methods: Seventy-two patients who had undergone single-level unilateral discectomy using two different methods, PELD and METRx-MD, between 2009 and 2011 were given a follow-up examination prospectively. Thirty-seven of these patients underwent discectomy using PELD, and the remaining 35 patients underwent discectomy using METRx-MD. In addition to the general parameters, clinical outcomes were assessed as specific parameters using the Visual Analogue Scale (VAS) score, the Oswestry Disability Index (ODI), the Short-form 36 (SF-36), and the return-to-work time.

Results: Sixty-seven percent (25/37) of the patients in the PELD group and 74\% (26/35) in the METRX-MD group were included in follow-up more than 6 months post-operatively. The mean improvements in the VAS scores for the back pain, leg pain, and ODI were 2.6, 4.8, and $30.1 \%$ for the PELD group and 2.8, 4.6, and $33.2 \%$ for the METRx-MD group, respectively. The SF-36 physical health component subscale score improved from 40.6 pre-operatively to 68.3 at the last follow-up for the PELD group post-operatively, and from 48.5 to 65.1 in the mental component subscale (METRx-MD group: from 34.4 to 66.5 and from 44.87 to 56.7). Complications occurred in 3/37 patients in the PELD group and in 2/35 patients in the METRx-MD group in the peri-operative period. The mean return-to-work times were 37.5 days in the PELD group and 42.5 days in the METRX-MD group.

Conclusion: The outcomes for the PELD group are comparable to those for the METRX-MD group. It can thus be concluded that PELD for lumbar disk herniations may be performed safely and effectively. Also, PELD can be considered one of the treatment modalities of lumbar disk herniation.
\end{abstract}

Key Words: Percutaneous discectomy $\cdot$ Microdiscectomy $\cdot$ Lumbar disc herniation $\cdot$ VAS $\cdot$ ODI $\cdot$ SF-36

\section{INTRODUCTION}

Lumbar discectomy for a herniated lumbar disc is the most commonly performed to relieve pain and to improve a neurological deficit. Various procedures for and types of treatment of lumbar disc disease have been introduced ${ }^{1)}$, and there have

- Received: July 30, 2012 - Revised: September 10, 2012

- Accepted: September 24, 2012

Corresponding Author: Dae-Hyun Kim, MD

Department of Neurosurgery, College of Medicine, Daegu Catholic

University, 3056-6 Daemyung 4Dong, Nam-gu, Daegu 705-718, Korea

Tel: +82-53-650-4258, Fax: +82-53-650-4392

Email: daehkim@cu.ac.kr been many changes in the treatment modality of lumbar disc herniation.

After Mixter and Barr reported the surgical treatment of lumbar herniated disc patients with laminectomy and discectomy in $1934^{32)}$, Caspar introduced the microsurgical technique in 1977. After minimally invasive techniques were applied to spinal surgery, Foley and Smith reported the performance of microendoscopic discectomy (MED) in $1997^{33)}$. In recent years, the use of tubular retractors in conjunction with the operating microscope or endoscope has become increasingly popular for the treatment of lumbar disc herniation, including of degenerative diseases ${ }^{2}$, and the development of an original MED instrumentation system led to the modification of the endoscopic approach to microdiscectomy using a microscope 
endoscopic tubular retractor system (METRx-MD) ${ }^{3)}$.

After the concept of minimally invasive surgery became more popular, Yeung et al. introduced standard transforaminal endoscopic surgery in $2002^{4}$, and minimally invasive techniques using endoscopy have increasingly been used to treat lumbar disc herniation, $3,5,6$. The development of the percutaneous endoscopic technique for lumbar disc disease represents an attempt to improve the operating efficacy, reduce the post-operative pain, limit the length of the patient's hospitalization, reduce perineural fibrosis, and minimize the development of spinal instability ${ }^{5,7,8)}$.

PELD has shown favorable results for the lumbar HNP in many previous reports. Although a physician may be certain of clinical improvement after PELD, it is difficult to measure the degree of improvement, including of the patients' quality of life. Moreover, the assessment of the results varies with the characteristics of the disease and the purpose of the surgery. Most previous studies used a qualitative scale (e.g., the modified Macnab criteria and the Odom scale) and showed good to excellent clinical outcomes after percutaneous endoscopic discectomy relevant to improvement in disease-related symptoms. These results were surgeon-based outcomes, however, which were not related to specific assessment of the patient's quality of life and functional status.

In this study, the clinical outcomes of classic PELD are compared with those of METRx-MD using VAS, ODI, SF-36, and the return-to-work time prospectively.

\section{MATERIALS AND METHODS}

\section{Patient population}

The prospective study involved 72 patients who had undergone single-level unilateral discectomy and whose results were analyzed statistically from 2007 to 2011 . The patients were divided into two groups according to the surgical methods. Thirty-seven patients underwent discectomy using PELD (Group I), and the remaining 35 patients underwent discectomy using METRx-MD (Group II).

The general inclusion criteria were as follows: (1) classic symptoms of lumbar radiculopathy, (2) no improvement after conservative treatment for 6-8 weeks; (3) only a onelevel pathologic lesion and no history of previous back surgery at the same level, and (4) no segmental instability in the dynamic flexion-extension radiography. The patients who had a severe neurologic deficit or spinal instability that required fusion, and other pathologic conditions such as fractures, tumors, or infections, were excluded from this study (Table 1).

MED was used for the patients with calcified discs, highly
Table 1. Data from 51/72 patients (25/37 in the PELD group and from 26/35 patients in the METRx-MD group) were included the follow-up data more than 6 months post-operatively. Data have male/female ratio, symptoms, main level, age in both groups

\begin{tabular}{lll}
\hline \hline Total patients & PELD & MED \\
\hline Age (years) & 45.88 & 56.46 \\
Male: Female ratio & $16: 9$ & $13: 13$ \\
Mean follow-up period (month) & 20 & 20 \\
Mean duration of & 1.8 & 2.79 \\
radiculopathy (month) & & \\
Symptoms & & \\
Back pain & $24(96 \%)$ & $24(92 \%)$ \\
Radicular pain & $25(100 \%)$ & $26(100 \%)$ \\
Motor deficit & $18(72 \%)$ & $15(57 \%)$ \\
Sensory deficit & $14(56 \%)$ & $13(50 \%)$ \\
Bowel/bladder dysfunction & 0 & 0 \\
Level & & \\
L1-2 & 0 & 0 \\
L2-3 & $1(4 \%)$ & $1(4 \%)$ \\
L3-4 & $6(24 \%)$ & $6(23 \%)$ \\
L4-5 & $13(52 \%)$ & $13(50 \%)$ \\
L5-S1 & $5(20)$ & $6(23 \%)$ \\
\hline
\end{tabular}

migrated disc herniations, severe degenerative lumbar changes, and some stenotic lesions at the same level.

\section{Clinical evaluation and follow-up}

The data on the maintained patients were analyzed prospectively. Such data were on the presence of back pain, radicular pain, a motor deficit, a sensory deficit, a reflex deficit, and bowel/bladder dysfunction pre-operatively and at the postoperative office visits. Office follow-ups were conducted 6 weeks, 3 months, 6 months, 12 months, and 24 months after the operation. The duration of a follow-up was extended when there were clinical symptoms. The examinations were performed by two physicians in the authors' clinic. In addition to a general examination, other information were obtained using the following parameters: the VAS scores for back pain and leg pain, the Oswestry Disability Index (ODI) for conditionspecific measurement, and Short-form 36 (SF-36) for the patients' quality of life and return-to-work time. If the patient was not followed up any more at the authors' institution, he or she reported the results to the authors post-operatively via a mail survey.

The complications were divided into two categories: major and minor, according to the classification scheme proposed by Carreon et $\mathrm{al}^{9)}$. The major complications were severe and had a negative effect on a patient's recovery. On the other hand, minor complications were not considered to have significantly affected the patient's recovery. 


\section{Statistical analysis}

The statistical analysis was performed with the use of SPSS version 19.0. A paired sample t-test and a Wilcoxon signed rank test were used to compare the differences between the pre- and post-operative parameters of the clinical outcomes for each group. Then two sample t-tests and Wilcoxon rank sum tests were used to compare the differences between the clinical results for the two groups. A $p$ value less than 0.05 was considered statistically significant.

\section{Surgical techniques}

In both groups, all the operations followed the standard method suggested in previous literature ${ }^{10,11)}$. In the PELD group, the procedure was performed under local or general anesthesia in the prone position on a radiolucent table for all the patients. The entry point of the needle was mostly positioned about $10 \mathrm{~cm}$ off the midline. After the infiltration of the entry point with local anesthetics, an 18-gauge spinal needle was inserted at the target point under the guidance of a fluoroscopic image. The target point was the mid-pedicular line on the anteroposterior image, and the posterior vertebral line on the lateral image. Then an epidurogram was taken using the contrast medium Isovist to confirm the location of the nerve root. After the insertion of the spinal needle into the disc, the degenerated herniated mass and disc were stained blue with indigocarmine for intra-operative identification. A tapered cannulated obturator was positioned using a guide wire. After touching the annulus, the obturator was positioned into the disc with hammering, a working cannula with a beveled opening was inserted along the obturator, and the obturator was removed. The blue-stained disc material was removed using small forceps and a radiofrequency probe (Ellman International, Hewlett, NY). After targeted fragmentectomy was performed, the complete device was removed, and finally, a sterile dressing and a one-point suture were applied (Fig. 1A, B). A2.8 mm working cannula was used without a laser and an endoscopic drill.

The lateral transforaminal access was generally chosen for the route to the spinal canal. There were limitations in the performance of the transforaminal procedures in some cases, however, which necessitated the use of the interlaminar approach. Especially, the herniations were technically inappropriate with the transformainal technique such as in downward highgrade migrating disc cases and some cases that involved L5-S1 with a high iliac crest. The entry point was the lateral edge of the interlaminar window under the guidance of a fluoroscopic
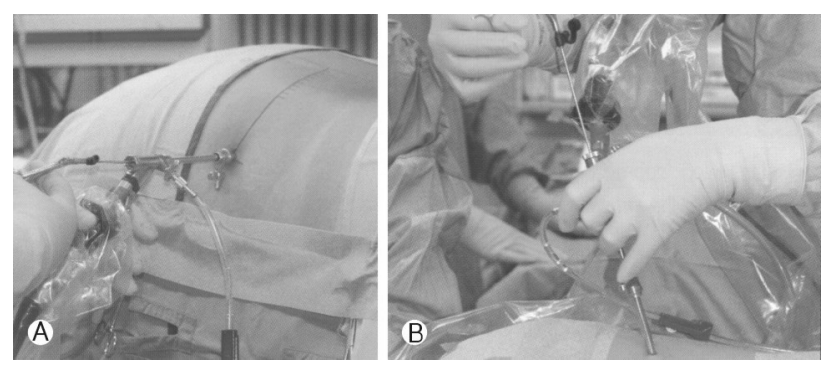

Fig. 1. In the PELD group, the procedure was performed in the prone position and disc material was removed using small forceps and radiofrequency probe.

image. During the approach, a lateral incision of the ligamentum flavum was made about $5 \mathrm{~mm}$ off the midline. After an epidurogram and a discogram were taken, discectomy was performed using the same process.

In the METRx-MD group, the procedure was performed under general anesthesia in the prone position on a radiolucent table in all the patients. After an about $2.5 \mathrm{~cm}$ skin incision was made, the paravertebral muscles were dissected using a serial dilator. The operating field was exposed using a tubular retractor. Under the microscopic view, partial hemilaminectomy and targeted fragmentectomy with discectomy were performed with retraction of the nerve root. After thorough decompression of the nerve root and the thecal sac was achieved, closure was performed in the conventional way.

\section{RESULTS}

\section{Baseline characteristics}

Data from 51/72 patients (25/37 in the PELD group and from 26/35 patients in the METRx-MD group) were included in the follow-up data more than 6 months post-operatively. Data from the remaining cases were lost due to the following reasons: 6 patients moved without a forwarding address, 12 patients did not respond to letters or telephone calls, 1 patient could not respond to the survey due to a medical problem (dementia), and 1 patient underwent revision-surgery with conventional spinal canal decompression at another hospital.

In the PELD group (Group I), there were 16 men and 9 women, and their mean age was 45.9 years (range: 13-70 years). The mean duration of their radiculopathy was 7.2 weeks, and their post-operative mean follow-up period was 23 weeks (range: 6-72 weeks). Ninety-six percent (24/25) of the patients experienced back pain preoperatively; 100\%(25/25), radicular pain; 88\%(22/25), a motor deficit; and 72\%(18/25), a sensory deficit. Preoperatively, there was no bowel/bladder dysfunc- 
tion and no reflex deficit (Table 1).

On the other hand, Group II included the 13 men and 13 women who underwent METRx-MD. Their mean age, the mean duration of their radiculopathy, and their post-operative mean follow-up period were 56.4 years (range: $32-79$ years), 10.9 weeks, and 21 weeks (range: 6-96 weeks), respectively. Clinical symptoms of back pain, radiating pain, motor deficit, and sensory deficit were noted in 92.3\% (24/26), 100\% (26/ 26), $81 \%(21 / 26)$, and $73 \%(19 / 26)$ of the patients, respectively. The most common symptom was radiating pain in the leg, and the most affected level was L4-5 in both groups (Table 1).

\section{Clinical outcomes}

In Group I, with regard to back pain, the mean pain discomfort scores that were measured on a VAS pre-operatively and at 6 weeks, 3 months, and the last office visit post-operatively were 4.57 (19 cases), 1.75 (12 cases), 1.54 (13 cases), and 1.96 (25 cases), respectively. With regard to leg pain, the mean VAS pain scores were 4.57 (19 cases), 2.25 (12 cases), 1.77 (13 cases), and 1.96 (25 cases), respectively. The ODI scores recorded during the same intervals were 46.15 (19 cases), 17.83 (12 cases), 13.71 (14 cases), and 16.12 (25 cases), respectively. The mean improvements in the VAS scores for back pain and leg pain were 2.6 and 4.8 , respectively, and the mean decreased ODI was $30.1 \%$. All these figures were statistically sig- nificant $(\mathrm{p}<0.05)$. The SF-36 physical healthy component subscale scores at the same intervals were 40.6 (19 cases), 56.1 (12 cases), 65.6 (14 cases), and 68.3 (25 cases), respectively. The SF-36 mental health component subscale scores during the same intervals were 48.5 (19 cases), 61.7 (12 cases), 64.8 (14 cases), and 65.1 (25 cases), respectively. They represent the improvements in the physical and mental component subscales by 27.7 and 16.6 , respectively, which are statistically significant, $(\mathrm{p}=0.02$ and $\mathrm{p}=0.04$, respectively) (Fig. $2 \mathrm{~A}, \mathrm{~B}, \mathrm{C}$, D, E, F).

In Group II, with regard to back pain, the mean pain discomfort scores measured on a VAS during the same intervals were 5.18 (22 cases), 2.11 (18 cases), 2.55 (18 cases), and 2.32 (26 cases), respectively. With regard to leg pain, the mean VAS pain scores were 7.13 (23 cases), 1.52 (18 cases), 2.11 (18 cases), and 2.53 (26 cases), respectively. The ODI scores recorded during the same intervals were 56.4 ( 25 cases), 29.5 (18 cases), 26.5 (18 cases), and 23.19 (26 cases), respectively. The mean improvements in the VAS scores for back pain and leg pain were 2.8 and 4.6, respectively, and the mean decreased ODI was 33.2\%. These figures are statistically significant $(\mathrm{p}<0.05)$. The SF-36 physical health component subscale score improved from 34.9 pre-operatively to 66.5 at the last follow-up in the METRx-MD group post-operatively, and the SF-36 mental health component subscale score improved from 44.9 to 56.7 with statistical significance $(\mathrm{p}=0.02)$ (Fig. 2. A,
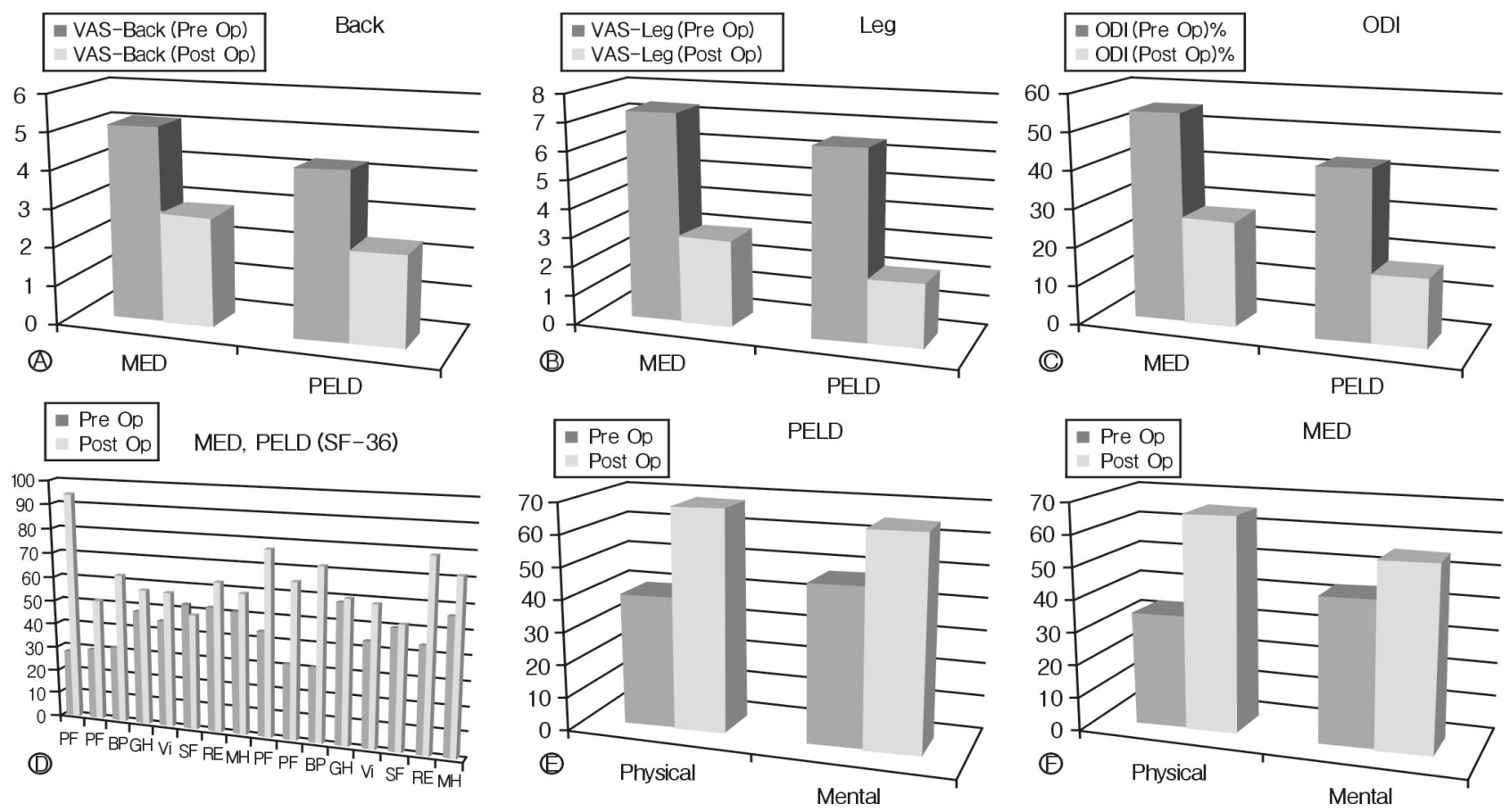

Fig. 2. Clinical outcomes were assessed as specific parameters using the Visual Analogue Scale (VAS) score, the Oswestry Disa bilityIndex (ODI), the Short-form 36 (SF-36). 
PELD, MED (Physical)

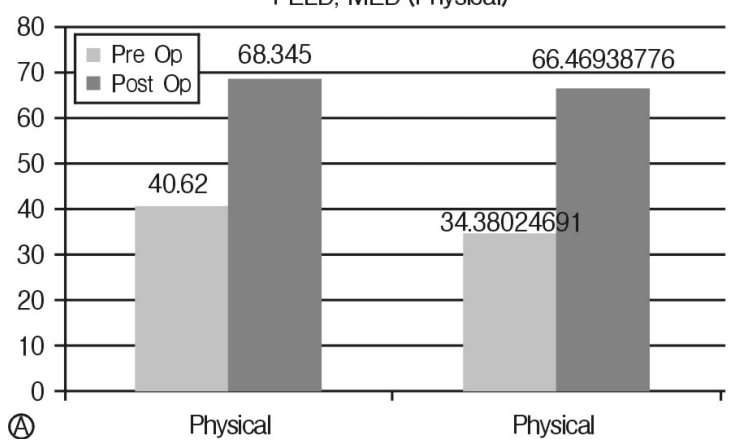

PELD, MED (Mental)

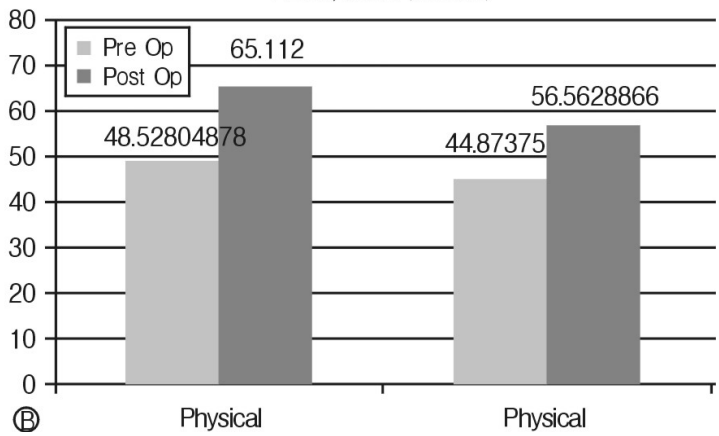

Fig. 3. Health-related quality of life means the effects of a patient's health on His/her overall well-being. In this study, the improvement of the SF-36 physical and mental health component subscale scores in the PELD/METRx-MD groups.

Table 2. Main complications and mean operative times, blood loss in PEDL group and METRx-MD group

\begin{tabular}{lcc}
\hline \hline & PELD & MED \\
\hline Mean blood loss (cc) & 35.2 & 153.8 \\
Mean OP time (min) & 141.7 & 178.8 \\
Hospital stay (day) & 9.32 & 13.2 \\
Complications & & \\
Superficial infection & 0 & 0 \\
Temporary N. root injury & 0 & 0 \\
Recurrent rate (\%) & $3(8.1 \%)$ & $2(5.7 \%)$ \\
Durotomy & $1(4 \%)$ & $1(4 \%)$ \\
Discitis & 0 & 0 \\
Postop.symptomatic Hx. & 0 & 0 \\
others(ex.Bowel violation) & 0 & 1 \\
\hline
\end{tabular}

B, C, D, E, F).

Both groups had negligible blood loss that had no significant clinical influence. The mean operative times were 141.7 minutes in Group I and 178.8 minutes in Group II-significantly shorter in Group I than in Group II $(\mathrm{p}=0.04)$. The mean hospital stay was significantly shorter in Group I (9.32 \pm 2.35 days $)$ than in Group II $(13.2 \pm 3.25$ days $)(\mathrm{p}<0.05)$ (Table 2).

Complications occurred in 3 patients (8.1\%) in Group I and 2 patients (5.7\%) in Group II. Dural tear occurred in 1 patient in Group I, which was successfully managed conservatively. It was covered with gelfoam intra-operatively, and the patient was given epidural steroid agents and needed bed rest for 48 hours. No delayed CSF fluid leaks or pseudomeningoceles developed. The other complication was the recurrence of the herniation at the same level and at the ipsilateral side. The extent of the reherniation was mild and the clinical symptom improved after the nerve root was blocked. A major complication was post-operative bowel violationin one patient. After the review of the operative video data, it was indefinite if the violation was relevant to the procedure. The patient was treated successfully after conservative therapy at the GS Depart- ment in the authors' institution.

On the other hand, the complications in Group II included two cases of a minor complication, for a complication rate of $5.7 \%$. There was 1 case of a minor complication of durotomy and 1 case of recurrence, which were treated successfully using the conservative method.

The return-to-work times of the previously employed patients were analyzed. All the patients who answered this survey went back to their previous job, and the mean return-to-work times were 37.8 days in Group I and 42 days in Group II.

\section{DISCUSSION}

Conventional microdiscectomy remains the gold standard for treating a herniated lumbar intervertebral disc. The disadvantages of open surgery, however, include extensive retraction and dissection of paraspinal muscles, a longer operatrive time, larger wounds, and bone resection ${ }^{12,13)}$. The development of microendoscopic discectomy (MED) has enabled many spinal surgeons, however, to perform lumbar discectomy reliably using a minimally invasive surgical approach. Among the them, microscopic lumbar discectomy with a tubular retractor was reported to have had good clinical outcomes in many previous studies ${ }^{2,3)}$. Moreover, PELD, as a less invasive modality, has several advantages over other forms of minimally invasive surgery, as follows: it more extensively preserves normal paraspinal structures during the surgery and reduces postoperative pain that usually makes early discharge possible, and it can be performed under local anesthesia ${ }^{14,15)}$.

Damage of stabilizing structures such as the paraspinal muscle was significantly reduced in the endoscopic group. Moreover, the ligamentum flavum did not have to be opened. In contrast, much greater damage of paraspinal structures is expected after the use of conventional techniques, which result in an epidural scar that makes revision operation more difficult ${ }^{10,16,17}$.

Many more patients in the METRx-MD group suffered from 
post-operative back pain. In the authors' current series, the VAS scores with regard to back pain after the surgery were much lower in the PELD group than in the METRx-MD group. Further muscle dissection and removal of posterior structures, such as the lamina and the facet joint, during microdiscectomy have been suggested to increase the risk of post-operative back pain ${ }^{18,19)}$. The more the resection of spinal canal structures is avoided, the more the operation-induced pain is reduced ${ }^{20,21)}$. The pain and work disability after the surgery were significantly reduced in the PELD group, but the reduction in the neurologic deficits could not be predicted on the basis of these results.

In this study, although almost all the patients underwent surgery after the induction administration of general anesthesia, a local anesthetic could also have been used ${ }^{8,10,22)}$. Four percent $(2 / 25)$ of the patients were put under local anesthesia, and 96\% (23/25), under general anesthesia. PELD can still be performed safely under general anesthesia for as long as the approach to the disc is appropriate, i.e., it is kept within the safety zone (Kambin's triangle). The advantage of general anesthesia is that there is no intra-operative pain and patient discomfort during the procedure, which makes the performance of the procedure safer than under local anesthesia ${ }^{23,24)}$.

In the early stages of a new surgical technique, surgeons have emphasized disability-related symptomatic relief and improvement after alternative therapies, and the clinical outcomes have included many factors, such as mortality, morbidity, and the re-operation rate. Studies of microscopy-assisted discectomy discussed various operating techniques and outcomes, but the success rates were generally high for herniated lumbar discs and showed good clinical results based on quantitative scale measurements such as the modified Macnab criteria and the Odom scale between $75 \%$ and $93 \%{ }^{25-27}$. Similar results were reported for percutaneous endoscopic operation ${ }^{4,8,12}$. Many excellent clinical outcomes have been reported in previous studies, but such results were surgeon-based outcomes that were not related to the patients' functional status and quality of life. These measures did not focus on the patient's perception of the influence of the operation on the patient.

To assess the impact on the quality of life of patients, various outcome questionnaires have been developed. The goal of these questionnaires is to measure patients' views of their health and daily activities. Health-related quality of life means the effects of a patient's health on his/her overall well-being ${ }^{28)}$. The most commonly used generic health-related quality of life survey is the SF-36 ${ }^{1,3)}$. In this study, the improvement of the SF-36 physical and mental health component subscale scores in the PELD group were 27.7 and 16.6, respectively, which agreed with the data in previous literature(Fig. 3A, B).

Also, significant improvements in back pain and leg pain were achieved in the PELD. The VAS scores for lower-back pain decreased from a mean of 4.57 before the surgery to 1.96 at the last follow-up. The VAS scores for leg pain decreased from 6.7 to 1.88 over the same period. Moreover, the back pain and neurogenic symptoms were very disabling and were associated with significant morbidity that affected the patient's quality of life. These improved scores in the outcome measurements mean a decrease in the impact of the disease on the patient's life and can also be translated into a significant improvement in the quality of life.

The mean decrease in the ODI in the Group I score was $30.1 \%$ at the final follow-up. The ODI is responsive to change in the clinical status. A reduction of at least 15 points in the ODI score was considered relevant to clinical improvement, as proposed by the Food and Drug Administration ${ }^{29)}$. Reductions in the ODI score were similar to those reported by Ruetten et al.10 and Yeung et al. ${ }^{4)}$ using the PELD technique.

Specific data such as the patient's hospital stay and return-to-work time are very important factors parameters of the assessment of the patient's quality of life. Although the relationship between these measures and the patient's health is uncertain, these factors may be related to an improvement in the patient outcome and productivity by reducing the duration of his/her disability ${ }^{1)}$. In this study, the mean hospital stay for PELD $(9.3 \pm 2.3)$ was longer than those reported in previous studies. Some other studies reported that endoscopic discectomy could be performed on an outpatient basis and on patients discharged within 24 hours. The median hospital stay of patients treated with conventional open discectomy ranges, however, from 3 to 4 days in other reports ${ }^{23)}$. The counting of the hospital stay in the authors' institution included the period of active ambulation after the prompt relief of the symptoms post-operatively. Actually, the interval time from the patient's discharge day to the his/her return-to-work day was much shorter in this study than in previous studies. This means the patient's disability time after his/her discharge from the authors' institution was reduced.

The other factor was the patient's ability to return to his/ her previous employment. Foley and Smith reported a mean return-to-work time of 17.6 days, and other studies reported that most of the patients were able to return to their previous occupation within 1 month and that the period of their disability was shorter with endoscopic discectomy than with microdiscectomy ${ }^{3,12,13)}$. All the patients in this study returned to their previous occupation, and their mean return-to-work time of 37.8 days is comparable with that in this series and shorter than those with METRx-MD (42.5 days).

The rates of recurrent disc herniation in the two groups were $2.7 \%(1 / 37)$ and $2.8 \%(1 / 35)$, respectively, and showed no statistically significant difference $(\mathrm{p}<0.01)$. The rates corre- 
spond to the data in the previous literature, and all the patients were treated successfully with the conservative method. The type of disc herniation and annular defect appeared related to the recurrence rate. A large annular defect caused a significantly higher recurrence rate than did a sequestrotomy or a smaller annular defect. The reduction in the operation-related annular defect has been discussed as a protective biomechanical factor $^{30,31)}$. It can be attempted with endoscopic discectomy. Moreover, in the case of a re-operation, the relatively large scar after open discectomy may complicate the dissection and increase the risk of nerve root damage due to adhesion.

In this study, the clinical outcomes, including the patient's quality of life, did not significantly differ between the two surgical techniques, and the quality of life and functional status of the patients in the PELD group were comparable with those of the patients in the METRx-MD group. Moreover, in terms of the post-operative back pain due to back muscle trauma and the recovery time, the PELD group had especially better outcomes. Thus, endoscopic surgery is seen as a sufficient and safe supplementation alternative to microsurgical procedures.

Although this study showed satisfactory clinical outcomes with PELD, it had some limitations. One of its limitations was its surgical method selection bias for the two groups. However, in the selective cases, the outcome of PELD might be comparable with those of METRx-MD. Endoscopic access was considered more appropriate for much younger patients with soft and extruding disc herniations than METRx-MD. This caused a lack of standardization of the two groups and insufficient investigation of the clinical outcomes for the two groups. This study also had relatively few cases and a shortterm follow-up period. Therefore, a further clinical study with PELD as the MIS is needed to determine the effectiveness and safety of PELD.

\section{CONCLUSION}

The PELD outcomes are comparable to the METRx-MD outcomes, even without the use of a laser. PELD is still being developed, and its indications have expanded from decompression of contained disks to more complicated cases. PELD for lumbar disk herniations may be performed safely and effectively, and PELD may be considered a treatment modality of lumbar disk herniation.

\section{REFERENCES}

1. Angevine PD, McCormick PC: Outcomes research and lumbar discectomy. Neurosurg Focus 13:E8, 2002

2. Parikh K, Tomasino A, Knopman J, Boockvar J, Hartl R: Operative results and learning curve: microscope-assisted tubular microsurgery for 1- and 2-level discectomies and laminectomies. Neurosurg Focus 25:E14, 2008

3. Palmer S: Use of a tubular retractor system in microscopic lumbar discectomy: 1 year prospective results in 135 patients. Neurosurg Focus 13:E5, 2002

4. Yeung AT, Tsou PM: Posterolateral endoscopic excision for lumbar disc herniation: surgical technique, outcome, and complications in 307 consecutive cases. Spine (Phila Pa 1976) 27:722731, 2002

5. Kambin P, O’Brien E, Zhou L, Schaffer JL: Arthroscopic microdiscectomy and selective fragmentectomy. Clin Orthop Relat Res 347:150-167, 1998

6. Onik G, Mooney V, Maroon JC, Wiltse L, Helms C, Schweigel $\mathrm{J}$, et al: Automated percutaneous discectomy: a prospective multiinstitutional study. Neurosurgery 26:228-232, 1990

7. Jang JS, An SH, Lee SH: Transforaminal percutaneous endoscopic discectomy in the treatment of foraminal and extraforaminal lumbar disc herniations. J Spinal Disord Tech 19:338343, 2006

8. Lew SM, Mehalic TF, Fagone KL: Transforaminal percutaneous endoscopic discectomy in the treatment of far-lateral and foraminal lumbar disc herniations. J Neurosurg 94:216-220, 2001

9. Carreon LY, Puno RM, Dimar JR $2^{\text {nd }}$, Glassman SD, Johnson JR: Perioperative complications of posterior lumbar decompression and arthrodesis in older adults. J Bone Joint Surg Am 85:2089-2092, 2003

10. Ruetten S, Komp M, Merk H, Godolias G: Full-endoscopic interlaminar and transforaminal lumbar discectomy versus conventional microsurgical technique: a prospective, randomized, controlled study. Spine (Phila Pa 1976) 33:931-939, 2008

11. Choi G, Lee SH, Lokhande P, Kong BJ, Shim CS, Jung B, et al: Percutaneous endoscopic approach for highly migrated intracanal disc herniations by foraminoplastic technique using rigid working channel endoscope. Spine (Phila Pa 1976) 33:E508515,2008

12. Mayer HM, Brock M: Percutaneous endoscopic discectomy: surgical technique and preliminary results compared to microsurgical discectomy. J Neurosurg 78:216-225, 1993

13. Hermantin FU, Peters T, Quartararo L, Kambin P: A prospective, randomized study comparing the results of open discectomy with those of video-assisted arthroscopic microdiscectomy. J Bone Joint Surg Am 81:958-965, 1999

14. Lee DY, Shim CS, Ahn Y, Choi YG, Kim HJ, Lee SH: Comparison of percutaneous endoscopic lumbar discectomy and open lumbar microdiscectomy for recurrent disc herniation. J Korean Neurosurg Soc 46:515-521, 2009

15. Lee DY, Ahn Y, Lee SH: Percutaneous endoscopic lumbar discectomy for adolescent lumbar disc herniation: surgical outcomes in 46 consecutive patients. Mt Sinai J Med 73:864-870, 2006

16. Annertz M, Jonsson B, Stromqvist B, Holtas S: No relationship between epidural fibrosis and sciatica in the lumbar postdiscectomy syndrome. a study with contrast-enhanced magnetic resonance imaging in symptomatic and asymptomatic patients. Spine (Phila Pa 1976) 20:449-453, 1995

17. Fritsch EW, Heisel J, Rupp S: The failed back surgery syndrome: reasons, intraoperative findings, and long-term results: a report of 182 operative treatments. Spine (Phila Pa 1976) 21:626-633, 
1996.

18. Ahn Y, Lee SH, Park WM, Lee HY, Shin SW, Kang HY: Percutaneous endoscopic lumbar discectomy for recurrent disc herniation: surgical technique, outcome, and prognostic factors of 43 consecutive cases. Spine (Phila Pa 1976) 29: E326-332, 2004

19. Ozgen S, Naderi S, Ozek MM, Pamir MN: Findings and outcome of revision lumbar disc surgery. J Spinal Disord 12:287292, 1999

20. Kotilainen E, Valtonen S: Clinical instability of the lumbar spine after microdiscectomy. Acta Neurochir (Wien) 125:120-126, 1993

21. Schoeggl A, Maier H, Saringer W, Reddy M, Matula C: Outcome after chronic sciatica as the only reason for lumbar microdiscectomy. J Spinal Disord Tech 15:415-419, 2002

22. Tsou PM, Yeung AT: Transforaminal endoscopic decompression for radiculopathy secondary to intracanal noncontained lumbar disc herniations: outcome and technique. Spine J 2:4148, 2002

23. Peng CW, Yeo W, Tan SB: Percutaneous endoscopic lumbar discectomy: clinical and quality of life outcomes with a minimum 2 year follow-up. J Orthop Surg Res 4:20, 2009

24. Peng CW, Yeo W, Tan SB: Percutaneous endoscopic discectomy: clinical results and how it affects the quality of life. J Spinal Disord Tech 23:425-430, 2010

25. Ebeling U, Reichenberg W, Reulen HJ: Results of microsurgical lumbar discectomy. Review on 485 patients. Acta Neurochir
(Wien) 81:45-52, 1986

26. Ferrer E, Garcia-Bach M, Lopez L, Isamat F: Lumbar microdiscectomy: analysis of 100 consecutive cases. Its pitfalls and final results. Acta Neurochir Suppl (Wien) 43:39-43, 1988

27. Andrews DW, Lavyne MH: Retrospective analysis of microsurgical and standard lumbar discectomy. Spine (Phila Pa 1976) 15:329-335, 1990

28. Gerszten PC: Outcomes research: a review. Neurosurgery 43: 1146-1156, 1998

29. Casal-Moro R, Castro-Menendez M, Hernandez-Blanco M, Bravo-Ricoy JA, Jorge-Barreiro FJ: Long-term outcome after microendoscopic diskectomy for lumbar disk herniation: a prospective clinical study with a 5-year follow-up. Neurosurgery 68:1568-1575, 2011

30. Wenger M, Mariani L, Kalbarczyk A, Groger U: Long-term outcome of 104 patients after lumbar sequestrectomy according to Williams. Neurosurgery 49:329-334, 2001

31. Zollner J, Rosendahl T, Herbsthofer B, Humke T, Eysel P: [The effect of various nucleotomy techniques on biomechanical properties of the intervertebral disk]. Z Orthop Ihre Grenzgeb 137: 206-210, 1999

32. Mixter WJ, Barr JS: Rupture of the intervertebral disc with involvement of the spinal canal. N Engl J Med:210-215

33. Foley KT, Smith MM: Microendoscopic discectomy. Techn Neurosurg 3:301-307, 1997 